\title{
Exploring the relationship between parcelization metrics and natural resource managers' perceptions of forest land parcelization intensity
}

\author{
Michael A. Kilgore \\ Professor \\ Director, Natural Resources Science and Management Graduate Studies \\ Department of Forest Resources \\ College of Food Agricultural and Natural Resource Sciences \\ University of Minnesota \\ 301K Green Hall \\ 1530 Cleveland Avenue North \\ St. Paul, Minnesota 55108-6112 \\ (phone) $\underline{612-624-6298}$ \\ (FAX) 612-625-5212 \\ mkilgore@umn.edu \\ Stephanie A. Snyder \\ Operations Research Analyst \\ USDA - Forest Service \\ Northern Research Station \\ 1992 Flowell Avenue \\ St. Paul, MN 55108 \\ (phone) 651-649-5294 \\ (FAX) 651-649-5107 \\ stephaniesnyder@fs.fed.us
}




\section{ABSTRACT}

A major challenge associated with forest land parcelization, defined as the subdivision of forest land holdings into smaller ownership parcels, is that little information exists on how to measure its severity and judge its impacts across forest landscapes. To address this information gap, an on-line survey presented field-based public natural resource managers in the Lake States of Minnesota, Wisconsin, and Michigan with four private forest ownership patterns, each containing the same total forest area, number of parcels, and average parcel size. Survey respondents ranked each landscape from most to least parcelized based on the degree to which each ownership pattern was perceived to adversely impact three forest-based goods and services: timber production, recreational access, and wildlife habitat. Using an exploded logit model, respondents' rankings of parcelization impact were found to be consistent, regardless of the forest good or service evaluated. Rankings were also not influenced by the respondent's professional discipline, location, length of professional experience, or employer. Of the four parcelization metrics evaluated, the Gini Coefficient and Adjusted Mean metrics appear to best capture the forest land ownership patterns that natural resource professionals are most concerned about, suggesting those metrics may be useful indicators by which to assess parcelization impact.

Key Words: Exploded Logit, Parcellation, Parcelization, Forest Ownership, Subdivision, Ranked Data 
2 Forest land parcelization is the subdivision of forest land holdings into smaller parcels. A major

3 challenge associated with understanding the effects of forest land parcelization is that little

4 information exists on when and to what degree forest land ownership patterns diminish the

5 production of forest-based goods and services. Specifically, the relationship between ownership

6 patterns and forest resource outputs is not well understood, and likely depends on the forest-

7 based good or service in question as well as the actions and management behaviors of the

8 landowners. Forest land parcelization has been linked to the loss of wildlife habitat (e.g., forest

9 land subdivision has been found to be a forerunner to forest habitat fragmentation, land

10 development, and road building), reduced timber availability (e.g., smaller parcel size has been

11 found to be less economical to harvest and associated with a decreased landowner interest in

12 management and investment), and greater restrictions on recreational access (e.g., smaller tracts

13 of forest land have been found to have a greater likelihood of being posted against public access)

14 (Dennis 1993, Theobald et al. 1997, Mehmood and Zhang 2001, Rickenbach and Gobster 2003,

15 Brooks 2003, Gobster and Rickenbach 2004, LaPierre and Germain 2005, King and Butler 2005,

16 Rickenbach and Steele 2006, Mundell et al. 2010). In sum, the parcelization literature makes

17 linkages between smaller parcel size and diminished ecosystem function or output. Yet, related

18 literature in the social sciences also suggests that different forest land ownership patterns may

19 impact forest-based goods and services as well (e.g., Vokoun et al. 2010).

20 There is also no agreed-upon measure or metric for judging and comparing the extent to which a

21 landscape has been parcelized, which creates difficulties when determining where and how to

22 prioritize efforts to minimize the effects of parcelization. In a previous study reported in this

23 journal, Kilgore et al. (2013) evaluated four parcelization metrics with respect to their similarity 
24 in quantifying the degree to which a forested landscape is parcelized. Their work illustrated that 25 each metric often describes a different intensity of parcelization for a given pattern of forest

26 ownership, attributed in large part to each metric capturing unique aspects of land tenure

27 arrangements within a landscape. They concluded that the choice of metric used to quantify

28 forest land parcelization within a landscape is a critical choice, but were unable to recommend a

29 universal metric due to the context-specific nature by which ownership patterns need to be

30 evaluated. This finding is in-line with efforts in the field of landscape ecology to identify

31 multiple metrics that can capture various spatial characteristics of landscape composition and

32 pattern (e.g., McGarigal and Marks 1995).

33 Additional research that relates forest ownership patterns with their associated impacts on forest-

34 based goods and services is needed. As a step towards addressing this need, we draw on the

35 perspectives and experiences of field-based natural resource managers in relating different forest

36 ownership patterns to their perceived impacts on different forest goods and services. Our

37 research examines the question of whether natural resource professionals perceive differences in 38 parcelization impact among select forest ownership patterns that vary by parcel size and pattern, 39 and whether their perceptions are influenced by their background and experience? Specifically, 40 we report on the findings of a study we conducted that examined rankings of forest land

41 parcelization impact by public natural resource managers. We also examine the relationship

42 between these rankings and several parcelization metrics that have been cited in the literature to 43 examine the metrics' ability (or usefulness) to capture changes in ecosystem goods and services 44 that are associated with changing forest ownership patterns.

\section{DATA AND METHODS}


46 A questionnaire was developed to solicit rankings from public natural resource managers of

47 select forest land ownership patterns based on the degree to which they believed each pattern

48 adversely impacts several forest resource goods and services. The questionnaire was part of a

49 broader survey that obtained resource manager perspectives and insights on various aspects of

50 forest land parcelization. Using modified Likert scale response items, public natural resource

51 managers provided parcelization-related information such as their familiarity with and degree of

52 parcelization activity in their work area, and important drivers and potential outcomes of

53 parcelization. The questionnaire also collected background information on the respondent (e.g.,

54 years of experience, state the respondent worked in, employer, professional discipline).

55 The questionnaire presented natural resource managers with four different private forest ownership patterns (Figure 1). The basis for selecting these four patterns and the forest goods

57 and services evaluated was feedback we received at an interactive scoping session with public natural resource field professionals in $\mathrm{MN}$ in 2012. In that session, participants evaluated a

59 number of different stylized and actual land ownership patterns, as well as a range of potential impacts associated with forest land parcelization. With respect to characterizing the impacts of

61 parcelization, participants indicated that stylized ownership patterns were easier to judge than

62 actual patterns, and that the patterns needed to reflect a wide range in individual parcel sizes.

63 The four patterns depicted include: 13 parcels representing considerable size heterogeneity

64 (Landscape A), 13 parcels of nearly equal size (Landscape B), one very large parcel covering

65 over $90 \%$ of the area and 12 equally-sized smaller parcels (Landscape C), and one large parcel

66 covering half of the area and 12 equally-sized smaller parcels (Landscape D). This

67 heterogeneity, particularly with respect to the size of the largest parcel in the landscape, tested 68 whether the degree of impact is associated with the size of the landscape's largest parcel (both 
69 the literature and the feedback we received at the scoping session suggests this larger parcels

70 play an important role in mitigating impacts).

71 To facilitate data analysis and the ability to compare rankings to average parcel size (the most

72 widely-cited parcelization metric), participants were informed that each of the four ownership

73 patterns contains the same total forest area (one section or 640 acres), number of parcels (13) and

74 average parcel size (49 acres) (similar to the average in the region), and that the landscape is

75 completely forested. The questionnaire instructed respondents to rank each landscape in terms of

76 the degree to which its land ownership pattern is perceived to adversely impact each of three

77 forest-based goods and services: timber production, recreational access, and wildlife habitat.

78 These three were selected because they were identified during the interactive scoping session as

79 those goods and services perceived to be most adversely impacted by forest land parcelization.

80 An on-line version of the questionnaire was developed using SurveyMonkey's Wufoo on-line

81 Form Creator (www.wufoo.com). The questionnaire was tested for functionality and

82 comprehension with three public natural resource professionals. A final version of the

83 questionnaire was prepared based on the feedback provided from the test.

84 The survey's target population was field-based public natural resource managers in the Lake

85 States, USA (Michigan, Wisconsin, Minnesota). This consisted of forestry, wildlife, recreation,

86 planning, and conservation professionals working for federal (i.e., USDA Forest Service and

87 Natural Resource Conservation Service, USDI Fish and Wildlife Service), state (i.e., state

88 departments of natural resources), and county/local (i.e., county land departments, soil and water

89 conservation districts) agencies. The region was selected due to the importance of its forests as a

90 source of raw materials for a diverse forest products industry and an important land cover in 
91 amenity-rich areas (e.g., lakes and rivers) that are attractive for recreation and second-home

92 development. The region also has been documented as an area where forest land parcelization

93 has been occurring (e.g., Gobster and Rickenbach 2004, Mundell et al. 2010, Kilgore et al.

94 2013).

95 Forest cover maps of each state were used to identify those areas in the region that are

96 predominantly forested. Government e-mail addresses for individuals working in the forested

97 regions of each state were obtained by searching agency websites and contacting agency

98 information officers. The final survey mailing list consisted of 773 e-mail addresses and

99 represented, to the best of our knowledge, a census of field-based public land natural resource

100 professionals working in the forested landscapes of the Lake States that met our selection

101 criteria.

102 The internet survey was administered in fall 2014. Survey administration generally followed the

103 protocols suggested by Dillman (2000). It consisted of a pre-survey e-mail to public agency

104 administrators (e.g., division directors) describing the study and informing them a questionnaire

105 would be sent to their field-based employees within the next week; a pre-survey e-mail to survey

106 recipients describing the study and indicating they would be receiving an on-line questionnaire

107 within the next few days; an email to survey recipients with a link to the on-line questionnaire;

108 and two follow-up reminder e-mails sent one and two weeks after the initial survey invitation,

109 respectively. For the questions on parcelization impact rankings, the survey produced 325 total

110 and 256 usable responses for a $42 \%$ total and $33 \%$ response rate, respectively. Only the usable

111 responses (Table 1) were used in the modeling analyses. Due to the anonymity of the responses,

112 opportunities to perform an analysis of nonresponse bias were limited. We compared usable

113 responses to survey recipients for each level of government and found no significant $\left(\chi^{2}=4.2, p\right.$ 
$114=0.157$ ) over or under representation (i.e., federal, state, and county/local employees constituted

$11531 \%, 52 \%$, and $17 \%$ of the survey and $25 \%, 55 \%$, and $20 \%$ of the usable responses,

116 respectively).

\section{Exploded Logit Model}

118 An exploded logit model (Allison and Christakis 1994, Allison 1999) was used to analyze the

119 ownership pattern rankings. The model, which is anchored in random utility theory, is derived

120 from a generalization of the conditional logit model and is used to analyze rank-ordered

121 preference data (Luce 1959, McFadden 1974). The exploded logit has been applied in marketing

122 research (e.g., Kamakura and Mazzon 1991), health and medical studies (e.g., Hsieh 2005,

123 Diederich et al. 2012), invasive species control (e.g., Paudel et al. 2007, Touza et al. 2014), and

124 the environmental economics literature (e.g., Montgomery 2002, Kumar and Kant 2007, Scarpa

125 et al. 2011).

126 In our survey, respondents were asked to rank the four ownership patterns based on how they

127 perceive each impacting three different forest-based goods and services. All respondents ranked

128 the landscapes for their impact on timber production first, followed by impact rankings for

129 recreational access and then for wildlife habitat. While we did not specifically offer (or prevent)

130 the option of tied rankings in the instructions, none of the respondents specified tied rankings.

131 Ten respondents provided incomplete ranks. Due to the computational challenge in handling

132 incomplete rankings and the small number in our dataset, these responses were removed.

133 Invoking the random utility theory framework, it is assumed that an individual, $i$, has preferences

134 over the set of landscapes, $J$, such that the utility derived from a choice $j, U_{i j}$, can be specified as:

$$
U_{i j}=u_{i j}+\epsilon_{i j}
$$


135 where $U_{i j}$ is the sum of a systematic component $u_{i j}$ and a random component $\boldsymbol{\epsilon}_{\mathrm{ij}}$. While the $U_{i j}$ 's

136 are unobserved, it is assumed that an individual will give landscape $j$ a 'higher' rank than

137 landscape $k$ whenever $U_{i j}>U_{i k}$.

138 The systematic component can be expressed as a linear function of explanatory variables:

$$
u_{i j}=\beta_{j} x_{i}
$$

139 where $\mathrm{x}_{\mathrm{i}}$ is a vector of attributes associated with the individual $i$ and $\beta_{j}$ is a vector of coefficients 140 associated with landscape $j$. The value of the $u_{i j}$ 's indicate the degree to which the respondent $i$ 141 'prefers' landscape $j$ (i.e., deems it to be more adversely impacting) over all of the other 142 landscape choices. Thus, in comparing landscapes 1 and 2, the odds of ranking landscape 1 over 143 landscape 2 is calculated by $\exp \left\{u_{i 1}-u_{i 2}\right\}$.

144 Where the exploded logit model specification deviates from the traditional multinomial logit 145 model is in the expansion or 'explosion' of a single observation of J-ranked alternatives into J-1 146 independent decisions, each based on a decreasing set of alternatives such that $\left(U_{i \mathrm{j}}>U_{i k}\right)$ can be 147 interpreted as $\left(U_{i 1}>U_{i j}, j=2\right.$ to $\left.J\right),\left(U_{i 2}>U_{i j}, j=3\right.$ to $\left.J\right)$, and $\left(U_{i 3}>U_{i j}, j=4\right.$ to $\left.J\right)$. The ranking 148 decisions are treated as a sequence of choices in which the landscape with the greatest 149 parcelization impact is chosen over all the other landscapes, then the landscape with the next 150 greatest parcelization impact is chosen over the remaining landscapes, and so on. Thus, the 151 respondents' ordering of the landscapes reflects the rank order of the utilities of the choices.

152 The likelihood function $\left(\mathrm{L}_{i}\right)$ for a single respondent is specified as follows following the random 153 utility model: 


$$
L_{i}=\prod_{j=1}^{J}\left[\frac{\exp \left\{u_{i j}\right\}}{\sum_{k=1}^{J} \delta_{i j k} \exp \left\{u_{i k}\right\}}\right]
$$

154 where $\delta_{i j k}=1$ if $Y_{i k}>Y_{i j}$ and 0 otherwise, where $Y_{i k}$ and $Y_{i j}$ are the ranks given to landscapes $k$ and $155 j$ by respondent $i$, respectively.

156 For a sample of $n$ independent respondents, the following log likelihood function is implied from 157 equation (3):

$$
\log L=\sum_{i=1}^{n} \sum_{j=1}^{J_{i}} u_{i j}-\sum_{i=1}^{n} \sum_{j=1}^{J_{i}} \log \left[\sum_{k=1}^{J_{i}} \delta_{i j k} \exp \left(u_{i k}\right)\right]
$$

158 The model was estimated using the partial likelihood procedure Proc PHREG in SAS 9.4 for 159 estimating proportional hazards models following Allison and Christakis (1994).

160 To allow ranked data, such as ours, to be analyzed with the exploded logit model, a dataset 161 stratified by the respondent needed to be prepared. That is, from our ranked landscape data, an 162 expanded dataset was developed in which a separate record was created for each respondent for 163 each of the four landscapes, for a total of 1,024 records. Each record consisted of a unique 164 identifier for each respondent, the ranking of the landscape, a dummy variable associated with 165 each landscape, and covariates associated with the respondents such as professional discipline 166 and years of experience.

167 Several exploded logit models were estimated. First, a model was run to test whether natural 168 resource professionals perceive any differences in the degree of parcelization impact among the 169 four landscapes. This test was accomplished by modeling three of the four dummy variables for 170 the landscapes as the independent variables with landscape $\mathrm{C}$ (Figure 1) as the reference 
171 category; i.e., the $u_{i j}=\beta_{j}$ for all $i$ and $j$, with one of the $\beta_{j}$ 's set to 0 as the selected reference

172 landscape. Additional models were run to evaluate whether the rankings were influenced by

173 attributes associated with the respondents rather than just random variation. Thus, separate

174 models were estimated to test the null hypotheses that the rankings do not vary by the

175 respondent's years of experience, state the respondent worked in, and/or professional discipline.

176 These models also included interaction terms (e.g., discipline*landscape, years of

177 experience*landscape) to test whether combinations of the covariates have a non-additive effect

178 on parcelization rankings.

179 In an attempt to better understand the relationship between the rankings of parcelization impact 180 and several parcelization metrics that have been cited in the literature, the following four metrics 181 were examined: mean parcel size, Shannon entropy index, Gini coefficient, and Adjusted Mean.

182 The Shannon entropy index and Gini coefficient are also used in the landscape ecology literature 183 to quantify landscape structure (McGarigal and Marks 1995). Mean parcel size is the average 184 size of all private forest land parcels in the landscape. The Shannon entropy index measures the 185 heterogeneity of forest parcels within landscape. The Gini coefficient also measures parcel size 186 distribution within a landscape. Adjusted Mean takes into account the number and spatial extent 187 of small parcels in a landscape. See Kilgore et al. (2013) for additional information on these 188 metrics. Ordinary least squares regression was used to examine the relationship between 189 exploded logit models' odds ratios and Gini, Shannon, and Adjusted Mean parcelization metrics.

\section{RESULTS}

191 Natural resource managers' rankings of the four landscapes with respect to how each ownership 192 pattern was perceived to impact timber production, wildlife habitat, and recreational access are 
193 shown in Table 2. An initial set of models was developed that allow for differences in rankings

194 across the four forest ownership patterns (landscapes), but not for differences across public

195 natural resource managers (Table 3). Global model tests for the null hypothesis that there are no

196 perceived differences in the impacts associated with the four landscape ownership patterns

197 produced a likelihood ratio chi-square statistic of 279 for the timber production model, 287 for

198 the wildlife habitat model, and 322 for the recreational access model, all with 3 degrees of

199 freedom. The $p$-values associated with these chi-square statistics are all less than 0.0001 , so we

200 reject the null hypothesis in all three instances. That is, natural resource managers perceive the

201 four ownership patterns to have differential effects on each of the three forest resource goods or

202 services evaluated: timber production, wildlife habitat, and recreational access.

203 Estimates of the $\beta_{j}$ model parameters for these three models are presented in Table 3 in the order

204 they were ranked by natural resource managers for each of the three forest resource goods and

205 services we evaluated. Note that all parameter estimates are in reference to Landscape C. The

206 parameter estimates tell us that natural resource managers perceive the ownership pattern

207 associated with Landscape B has the greatest adverse impact on all three forest goods and

208 services evaluated (timber production, wildlife habitat, recreational access), with the ownership

209 pattern represented in Landscape C having the least adverse effects on these forest resources.

210 The $\beta_{j}$ values represent the difference in log odds relative to Landscape C. For example, the odds

211 that natural resource managers perceived Landscape B to have greater adverse impact on timber

212 production is 4.62 times the odds of perceiving Landscape $\mathrm{C}$ as having greater adverse impacts

$213\left(\mathrm{e}^{1.53}=4.62\right)$. Similarly, the odds that natural resource managers perceived Landscape A to have

214 greater adverse impact on wildlife habitat is 2.72 times the odds of them perceiving Landscape C 
215 as having greater adverse impacts). Note that comparisons between any two land ownership

216 patterns can be made by exponentiating the differences in the parameter estimates.

217 The rankings for all but three pairwise landscape comparisons are significantly different $(p$ -

218 values less than 0.0001) (Table 3). Rankings of parcelization impact are not significantly

219 different $(\alpha \leq 0.05)$ between Landscapes A and D with respect to their impacts on timber

220 production, wildlife habitat and recreational access. The parameter estimates for the three models

221 also tell us that public natural resource managers consistently ranked the four landscapes from

222 most to least adverse impactful, regardless of the forest good or service they evaluated. In other

223 words, the ownership pattern associated with Landscape B was always considered to have the

224 greatest adverse impacts, while the ownership pattern associated with Landscape C was

225 consistently perceived to be least adverse with respect to its impact on timber production,

226 wildlife habitat, and recreational access.

227 Additional models were developed to test the null hypothesis that natural resource professionals'

228 perceptions of forest parcelization impact are not influenced by their background and experience.

229 Specifically, the models tested whether rankings of parcelization impacts are associated with the

230 respondent's employer (e.g., federal natural resource agency), discipline focus (e.g., forest

231 management), or geographic location (e.g., Minnesota), as well as interactions among these

232 variables. None of the models provide additional information on how or whether these variables

233 influence the respondents' perceptions of the different ownership patterns impact on timber

234 production, wildlife habitat, and recreational access, so we cannot reject the null hypothesis.

235 Stated differently, the respondents' state of residence, employer, and professional discipline has

236 no statistically significant effect $(\alpha \leq 0.05)$ on their ranking preferences. 
237 Table 3 also contains the values of each of the four parcelization metrics examined by Kilgore et

238 al. (2013) for the four ownership patterns evaluated by public natural resource managers. The

239 Adjusted Mean and Shannon indices are both positively correlated with the respondents'

240 perceptions of parcelization impacts, while the Gini coefficient is inversely related to their

241 rankings (by definition in how the Gini is specified). Mean parcel size is constant across the four

242 landscapes.

243 Figure 2 depicts the relationship between the odds ratios associated with the parameter estimates

244 for the three models described in Table 3 and the Gini, Shannon, and Adjusted Mean values for

245 the four land ownership patterns evaluated. While all three metrics are strongly associated with

246 the ranking preferences of natural resource professionals, Gini and Adjusted Mean have the

247 strongest linear correlation with the model-derived odds ratios across the three forest goods and

248 services evaluated. In other words, these two metrics best capture the rankings of how our

249 respondents viewed the four forest ownership patterns presented to them with respect to their

250 impacts to timber production, wildlife habitat, and recreational access.

\section{DISCUSSION AND CONCLUSIONS}

252 Our research sought to improve our understanding of how different private forest land ownership 253 patterns are perceived to impact the ability of forests to provide different goods and services. By

254 evaluating public natural resource professionals' perceptions of parcelization impact associated

255 with different patterns of land ownership, we were able to characterize which of the four

256 ownership patterns are perceived to have the most deleterious effects on three forest-based goods

257 and services: timber production, wildlife habitat, and recreational access. We were also able to

258 examine how several parcelization metrics explored in earlier research (and in the landscape 
259 ecology literature) relate to perceptions of impact that are associated with different forest land

260 ownership patterns. To our knowledge, neither analysis has previously been reported in the

261 literature.

262 We found that rankings of parcelization impact do not change, regardless of whether the impacts 263 are in reference to timber production, wildlife habitat, or recreational access. We further found

264 that these rankings are not influenced by several factors that vary across the population of public

265 natural resource managers in the Lake States such their professional training, location,

266 professional experience, or employer.

267 We determined that several parcelization metrics align with the rankings of parcelization impact

268 provided by our survey respondents. In particular, the values associated with the Gini and

269 Adjusted Mean metrics are very highly correlated with the log odds associated with each of our

270 model's parameter estimates. This suggests that, of the metrics we evaluated, these two best

271 capture the forest land ownership patterns that public natural resource professionals are most

272 concerned about with respect to their impact on timber production, wildlife habitat, and

273 recreational access. As such, they may be useful indicators of the effects of parcelization.

274 Judging by the rankings, the landscape containing the largest intact holding is viewed to be least 275 impactful, irrespective of the amount of ownership fragmentation or the size of ownerships that 276 surround this parcel. For example, public natural resource professionals regarded Landscape C, 277 with a single 587 acre parcel, as having the least adverse impact on timber production, wildlife 278 habitat, and recreational access, even though it has more extremely small parcels than the other 279 three landscapes. 
Yet, the size of the largest patch is a not always a good indicator of parcelization impacts. For example, Landscape D (with half of the surface area in a single parcel) and Landscape A (the largest parcel captures less than $19 \%$ of the total surface area) were ranked equally in terms of the impacts on timber production, wildlife habitat, and recreational access. This suggests there may be a threshold size for the dominant parcel (percent of surface area within a landscape) below which its ability to mitigate the impacts of parcelization is limited. It also may suggest there may be other factors at play other than the size of the dominant parcel. For example, Vokoun et al.(2010) found that incremental increases in the number of private individuals bordering a parcel increased landowner willingness to consider jointly planning forest management with neighbors (e.g., conduct a timber harvest, improve habitat). This could help explain why Landscape A, with a larger number of adjacent owners to individual parcels, is perceived to have the same level of impact as Landscape D, even though the latter contains a much larger single, contiguous parcel.

The strong correlation between the parcelization impact rankings and Gini and Adjusted Mean values suggests these metrics may have important practical use to natural resource managers. To the extent this relationship exists, the metrics can help identify those areas within a landscape whose ownership patterns are most/least likely to impair forest function. Knowing where these areas are can assist managers in prioritizing efforts aimed at reducing parcelization impacts. Such efforts might include fee acquisition or conservation easements to protect large, contiguous holdings from subdivision, land use zoning that establishes minimum parcel and development standards, and property tax programs that provide financial relief to landowners who meet certain ownership and/or land management requirements. Additional research is needed to examine how well these metrics relate to perceptions of impact across a wider range of 
ownership configurations than the four patterns evaluated in this study. Likewise, further research might test the applicability of other indices used to describe habitat fragmentation as a measure of parcelization impacts.

Our findings need to be interpreted with some caution. We assumed survey participants were presented with a sufficient number and types of ownership patterns that would enable them to identify differential impacts for each forest-based good or service in question. We also assumed the ownership patterns we presented were realistic, and that respondents knew enough about parcelization impacts to provide meaningful, differentiated responses, both according to the ownership patterns they evalauted and the goods and services impacted by parcelization. We are doubtful all of these assumptions were fully met. Follow-up research is needed to evaluate the validity of these assumptions. Additionally, our study only surveyed public natural resource professionals in a three-state area. Research that examines the relationship between ownership patterns and their impacts in other parts of the country and includes perspectives beyond public natural resource managers (e.g., private landowners) is needed to determine the extent to which our findings have broader applicability.

We view our research as an initial attempt to correlate natural resource professionals' rankings of parcelization impacts for a specific forest output or use such as timber to different parcelization metrics assigned to the same landscapes. While we view this work as exploratory, the results are informative in that they describe how landscapes containing certain ownership features (e.g., one large parcel among several small ones) are viewed relative to their impact on various forest goods and services. We believe this research could be a precursor to a more in-depth study where, with the help of a multi-disciplinary team of scientists, forest ownership patterns and the associated parcelization metrics can be more precisely linked to specific landowner actions and 
326 their economic or ecological effects (e.g., inability to sustain commercial timber harvesting,

327 water quality degradation). Such research would advance our understanding of how to more

328 precisely measure the impact land ownership patterns have on a specific forest good or service.

\section{REFERENCES}

330 Allison, P.D. 1999. Logistic Regression Using the SAS system: Theory and Application. Cary, $331 \quad$ NC: SAS Institute, INC.

332 Allison, P.D., and N.A. Christakis. 1994. Logit models for sets of ranked items. Sociological $333 \quad$ Methodology 24:199-228.

334 Beggs, S., Cardell, S., and J. Hausman. 1981. Assessing the potential demand for electric cars. $335 \quad$ Journal of Econometrics 16:1-19.

336 Brooks, R.T. 2003. Abundance, distribution, trends, and ownership patterns of early 337 successional forests in the northeastern United States. Forest Ecology and Management 338 185(2003): 65-74.

339 Chapman, R., and R. Staelin. 1982. Exploiting rank ordered choice set data within the stochastic 340 utility model. Journal of Marketing Research 19: 288-301.

341 Dennis, D.F. 1993. An empirical study of posting private nonindustrial forests, Wildlife Society 342 Bulletin 21: 6-10.

343 Diederich, A., Swait, J., and N. Wirsik. 2012. Citizen participation in patient prioritization policy 344 decisions: An empirical and experimental study on patients' characteristics. PLoS ONE, 7(5), 345 e36824.doi:10.1371/journal.pone.0036824. 
346 Dillman, D.A. Mail and internet surveys: The tailored design method. Vol. 2. New York:

$347 \quad$ Wiley, 2000.

348 Gobster, P.H., and M.G. Rickenbach. 2004. Private forestland parcelization and development in 349 Wisconsin's Northwoods: perceptions of resource-oriented stakeholders. Landscape and $350 \quad$ Urban Planning 69:165-182.

351 Hausman, J.A., and P.A. Ruud. 1987. Specifying and testing econometric models for rank352 ordered data. Journal of Econometrics 34:83-104.

353

354

355

356

357

358

359

360

361

362

Hsieh, C-M. 2005. Age and relative importance of major life domains. Journal of Aging Studies 19:503-512.

Kamakura, W.A., and J.A. Mazzon. 1991. Value segmentation: A model for the measurement of values and value systems. Journal of Consumer Research 18: 208-218.

Kilgore, M.A., S.A. Snyder, K. Block-Torgerson, and S.J. Taff. 2013. Challenges in characterizing a parcelized forest landscape: why metric, scale, and threshold matter. Landscape and Urban Planning 110(2013): 36-47.

King, S.L., and B.J. Butler. 2005. Generating a forest parcelization map for Madison County, NY. In: Bevers, M., Barrett, T.M. (Eds.), Systems Analysis in Forest Resources: Proceedings of the 2003 Symposium, General Technical Report PNW-GTR-656. USDA Forest Service, Pacific Northwest Research Station, Portland, OR, pp 147-155.

Kumar, S., and S. Kant. 2007. Exploded logit modeling of stakeholders' preferences for multiple forest values. Forest Policy and Economics 9: 516-526. 
LaPierre, S., and R.H. Germain. 2005. Forestland parcelization in the New York City watershed. Journal of Forestry 103(3): 139-145.

Luce, R. 1959. Individual Choice Behavior: A Theoretical Analysis. John Wiley and Sons, Inc. New York.

McFadden, D. 1974. Conditional logit analysis of qualitative choice behavior. In: Frontiers in Econometrics, edited by Paul Zarembka, pg. 105-142. New York: Academic Press.

McGarigal, K., and B.J. Marks. 1995. FRAGSTATS: spatial pattern analysis program for quantifying landscape structure. Gen. Tech Rep. PNW-GTR-351. Portland, OR: U.S. Department of Agriculture, Forest Service, Pacific Northwest Research Station, 122 p.

Mehmood, V.C., and D. Zhang. 2001. Forest parcelization in the United States: a study of contributing factors. Journal of Forestry 99(4): 30-34.

Montgomery, C.A. 2002. Ranking the benefits of biodiversity: An exploration of relative values. Journal of Environmental Management 65: 313-326.

Mundell, J., S. Taff, M. Kilgore, and S. Snyder. 2010. Using real estate records to assess forest land parcelization and development: a Minnesota case study. Landscape and Urban Planning 94 (2010) 71-76.

Paudel, K.P., Dunn, M.A., Bhandari, D., Vlosky, R.P., and K.M. Guidry. 2007. Alternative methods to analyze the rank ordered data: A case of invasive species control. Natural Resources Modeling 20(3): 451-471. 
385 Punj, G., and R. Staelin. 1978. The choice process for graduate business schools. Journal of Marketing Research 15: 588-598.

387 Rickenbach, M.G., and P.H. Gobster. 2003. Stakeholders' perceptions of parcelization in 388 Wisconsin's northwoods. Journal of Forestry 101(6): 18-23.

389

390

391

392

393

394

Richenbach, G.G, and T.W. Steele. 2006. Logging firms, nonindustrial private forests, and forest parcelization: evidence of firm specialization and its impact on sustainable timber supply. Canadian Journal of Forest Research 26(2006): 186-194.

Scarpa, R., Notaro, S., Louviere, J., and R. Raffaelli. 2011. Exploring scale effects of best/worst rank ordered choice data to estimate benefits of tourism in alpine grazing communities. American Journal of Agricultural Economics 93(3): 813-828.

Theobald, D.M., J.R. Miller, N.T. Hobbs. 1997. Estimating the cumulative effects of development on wildlife habitat. Landscape and Urban Planning 39(1): 25-36.

Touza, J., Pérez-Alonso, A., Chas-Amil, M.L., and K. Dehnen-Schmutz. 2014. Explaining the rank order of invasive plants by stakeholder groups. Ecological Economics 105: 330-341.

Vokoun, M., G.S. Amacher, J. Sullivan, and D. Wear. 2010. Examining incentives for adjacent non-industrial private forest landowners to cooperate. Forest Policy and Economics 12(2010): 104-110. 
404 Table 1. Usable survey responses by professional discipline and unit of government.

405 Table 2. Natural resource managers' rankings of ownership patterns according to perceived 406 degree of adverse impacts on timber production, wildlife habitat, and recreational access.

407 Table 3. Exploded logit model results describing natural resource managers' rankings of 408 ownership patterns according to perceived degree of adverse impacts on timber production, 409 wildlife habitat, and recreational access. 


\section{LIST OF FIGURES}

412 Figure 1. Forest ownership patterns ranked by public natural resource managers for their

413 perceived adverse impact on timber production, recreational access, and wildlife habitat.

414 Figure 2. Relationship between exploded logit models' odds ratios and Gini, Shannon, and

415 Adjusted Mean parcelization metrics.

416 

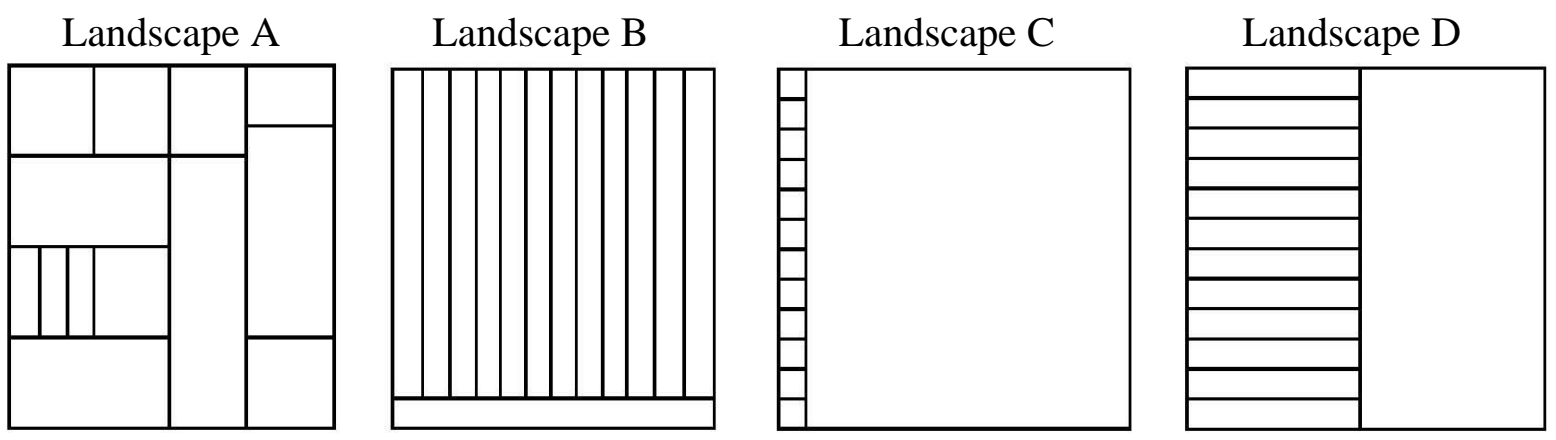

419

421

Figure 1. Forest ownership patterns ranked by public natural resource managers for their perceived adverse impact on timber

422 production, recreational access, and wildlife habitat. The managers were informed that each landscape has the same area (640 acres),

423 number of parcels (13) and average parcel size (49 acres) and is completely forested.

424 

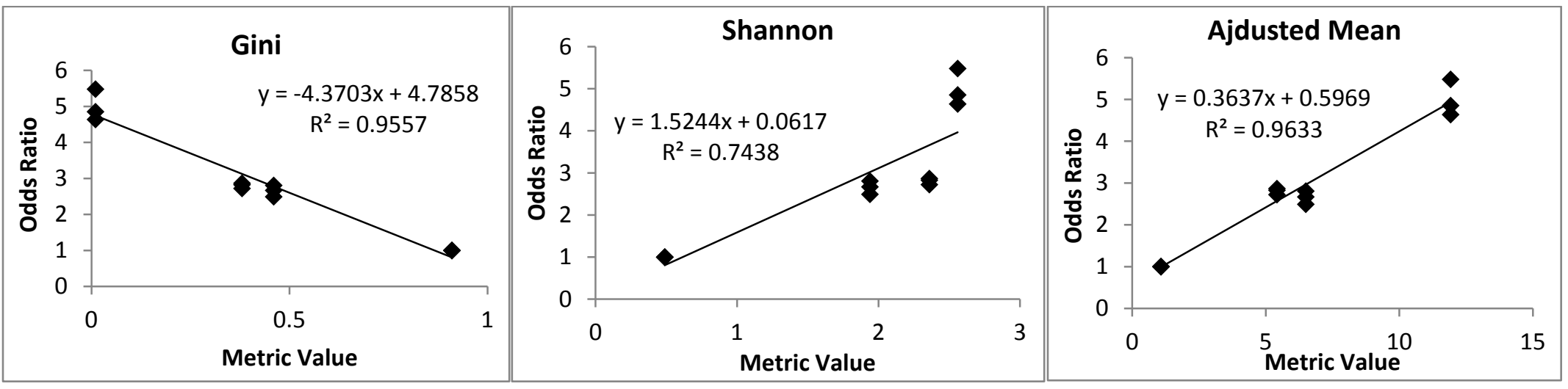

427

Figure 2. Relationship between exploded logit models' odds ratios and Gini, Shannon, and Adjusted Mean parcelization metrics.

428

429 
Table 1. Usable survey responses by professional discipline and unit of government.

\begin{tabular}{|l|r|r|r|r|}
\hline & Federal & State & County/Local & TOTAL \\
\hline Forest Management & 11 & 99 & 44 & 154 \\
\hline Wildlife Management & 4 & 39 & 1 & 44 \\
\hline Soil \& Water Conservation & 32 & 0 & 2 & 34 \\
\hline Natural Resource Planning & 14 & 2 & 2 & 18 \\
\hline Other & 3 & 2 & 1 & 6 \\
\hline TOTAL & 64 & 142 & 50 & 256 \\
\hline
\end{tabular}

$431{ }^{1}$ includes forest ecology and forest recreation disciplines.

432

433

434

435

436 
438 production, wildlife habitat, and recreational access. Perceived greatest adverse impacts are assigned a rank of 1; perceived least

439 adverse impacts are assigned a rank of 4. Values represent percent of time rank was assigned. Percentages may not always total 100

440 due to rounding.

\begin{tabular}{|c|c|c|c|c|c|c|c|c|c|c|c|c|}
\hline & \multicolumn{3}{|c|}{ Landscape A } & \multicolumn{3}{c|}{ Landscape B } & \multicolumn{3}{c|}{ Landscape C } & \multicolumn{3}{c|}{ Landscape D } \\
\hline Rank & Timber & $\begin{array}{c}\text { Wildlife } \\
\text { Habitat }\end{array}$ & $\begin{array}{c}\text { Rec } \\
\text { Access }\end{array}$ & Timber & $\begin{array}{c}\text { Wildlife } \\
\text { Habitat }\end{array}$ & $\begin{array}{c}\text { Rec } \\
\text { Access }\end{array}$ & $\begin{array}{c}\text { Timber } \\
\text { Habitat }\end{array}$ & $\begin{array}{c}\text { Rec } \\
\text { Access }\end{array}$ & $\begin{array}{c}\text { Wildlife } \\
\text { Timber }\end{array}$ & $\begin{array}{c}\text { Rec } \\
\text { Habitat }\end{array}$ \\
\hline 1 & 13 & 13 & 13 & 76 & 77 & 79 & 11 & 9 & 8 & 0 & 1 & 1 \\
\hline 2 & 46 & 41 & 40 & 13 & 13 & 12 & 2 & 2 & 1 & 39 & 45 & 47 \\
\hline 3 & 36 & 39 & 40 & 1 & 2 & 2 & 4 & 6 & 7 & 59 & 52 & 50 \\
\hline 4 & 5 & 6 & 6 & 9 & 9 & 7 & 83 & 83 & 85 & 2 & 2 & 2 \\
\hline
\end{tabular}

441 
444 degree of adverse impacts on timber production, wildlife habitat, and recreational access.

\begin{tabular}{|l|c|c|c|c|c|c|c|}
\hline & Timber & Wildlife & Recreational & \multicolumn{4}{|c|}{ Parcelization Metrics } \\
\cline { 5 - 8 } Private Forest & Production & Habitat & Access & & Adjusted & \\
Ownership Pattern & $\beta_{j}$ & $\beta_{j}$ & $\beta_{j}$ & Gini & Mean & Shannon & Mean \\
\hline Landscape B & 1.53 & 1.58 & 1.70 & 0.01 & 11.92 & 2.56 & 49.00 \\
\hline Landscape A & 1.04 & 1.00 & 1.05 & 0.38 & 5.42 & 2.36 & 49.00 \\
\hline Landscape D & 0.91 & 0.98 & 1.03 & 0.46 & 6.50 & 1.94 & 49.00 \\
\hline Landscape C & 0.00 & 0.00 & 0.00 & 0.91 & 0.49 & 0.49 & 49.00 \\
\hline Global Model & $\chi^{2}=279$ & $\chi^{2}=287$ & $\chi^{2}=322$ & & & & \\
Statistics & $p<0.001$ & $p<0.001$ & $p<0.001$ & & & & \\
& -2 LL $=12867$ & -2 LL $=12691$ & -2 LL $=12778$ & & & & \\
\hline
\end{tabular}

